Check for updates

Cite this: RSC Adv., 2017, 7, 45351

\title{
Separation of rare-earth ions from ethylene glycol (+LiCl) solutions by non-aqueous solvent extraction with Cyanex 923†
}

\author{
Nagaphani Kumar Batchu, ${ }^{a}$ Tom Vander Hoogerstraete, (D) Dipanjan Banerjee ${ }^{\mathrm{b}}$ \\ and Koen Binnemans (D) *a
}

\begin{abstract}
The separation of a mixture of rare earths by non-aqueous solvent extraction with two immiscible organic phases has been studied. The more polar organic phase was ethylene glycol with dissolved lithium chloride and the less polar organic phase was the extractant diluted in $n$-dodecane. Cyanex 923 was found to be the most performant extractant amongst the investigated acidic, basic and solvating extractants: Cyanex 272, Cyphos IL 101, Aliquat 336, bis(2-ethylhexyl)amine, trioctylphosphine oxide (TOPO) and Cyanex 923. The replacement of the aqueous chloride feed solutions by non-aqueous ethylene glycol feed solutions had a profound effect on the distribution ratios and separation factors. The separation factors for extraction of pairs of rare earths from aqueous chloride solutions by Cyanex 923 are too low to be of practical use. On the contrary, a mixture of rare earths can be separated conveniently in four different groups by extraction with Cyanex 923 from ethylene glycol $(+\mathrm{LiCl})$ solutions. The influence of several parameters such as the chloride concentration, the type of chloride salt, the addition of other polar solvents to the ethylene glycol phase, the addition of second extractant to the less polar organic phase, and the addition of complexing agents to the ethylene glycol phase has been studied. The extraction mechanism for extraction of ytterbium(III) was studied by slope analysis experiments. The ytterbium(III) species in the ethylene glycol phase and the extracted species in the $n$-dodecane phase were determined by EXAFS. Furthermore, a conceptual flow sheet for the fractionation of rare earths from an ethylene glycol (+LiCl) feed solution into different groups by extraction with Cyanex 923 has been proposed. The new extraction system is useful for extraction of scandium and for separation of scandium from the other REEs.
\end{abstract}

Received 18th August 2017 Accepted 16th September 2017 DOI: $10.1039 / c 7 r a 09144 c$ rsc.li/rsc-advances

\section{Introduction}

Solvent extraction is widely used for the separation of mixtures of rare-earth elements (REEs) on an industrial scale. ${ }^{\mathbf{1}-5}$ However, the separation processes are not very efficient because the separation factors between adjacent REEs are small, on average only 1.5 to 2 . Often more than 1000 mixer-settlers are required to separate a mixture containing all the REEs into individual REEs with a purity of more than 99.9\%. Additionally, most flow sheets for the separation of REEs are not environmentally friendly. When the separations are carried out with acidic extractants such as substituted phosphoric, phosphonic or phosphinic acids, large amounts of chemicals are consumed for

${ }^{a}$ KU Leuven, Department of Chemistry, Celestijnenlaan 200F, B-3001 Leuven, Belgium. E-mail: Koen.Binnemans@kuleuven.be; Tel: +32 16327446

${ }^{b}$ Dutch-Belgian Beamline (DUBBLE), ESRF - The European Synchrotron, CS 40220, F38043 Grenoble Cedex 9, France

$\dagger$ Electronic supplementary information (ESI) available: Viscosity of the rare-earth feed solution as a function of the LiCl concentration and the temperature. Recycling and reuse of $1 \mathrm{M}$ Cyanex 923 for the extraction and stripping of $\mathrm{Yb}$ (III) for five cycles. See DOI: 10.1039/c7ra09144c
$\mathrm{pH}$ control and for stripping of REEs from the loaded organic phase, and also large volumes of waste water are generated. Another issue with the use of some acidic extractants such as bis(2-ethylhexyl)phosphoric acid (D2EHPA) is that the concentration of the REEs in the loaded organic phase cannot be too high, because otherwise gel formation will occur. Therefore, the aqueous feed solution cannot be too concentrated and large volumes of feed solution have to be used for separation of bulk quantities of REEs. When neutral extractants such as tri- $n$-butyl phosphate (TBP) or basic extractants such as Aliquat 336 are used, much higher metal loadings of the organic phase are possible and stripping can be achieved easily by water, but these extractants can extract REEs only efficiently from nitrate feed solutions and not from chloride feed solutions. $\mathrm{HNO}_{3}$ is much more expensive than $\mathrm{HCl}$, and treatment of nitrate-containing aqueous waste streams is more difficult than treatment of chloride-containing aqueous waste streams.

The difficulties related to the separation of REEs makes that solvent extraction of REEs are an active field of research. Different routes are being explored. A first approach is the addition of a second extractant to the organic phase to enhance the distribution ratios and the separation factors. ${ }^{6-10}$ This 
approach is called synergistic solvent extraction. A second approach is the addition of complexing agents to the aqueous phase. ${ }^{11-14}$ A third approach is to design new ligands for the extraction of metals..$^{15-17}$ Undiluted ionic liquids are starting to attract more and more attention for the separation and purification of REEs. ${ }^{\mathbf{1 1}, \mathbf{1 8 - 2 3}}$ All these research efforts are focusing on modifications of the existing aqueous and organic phase in conventional solvent extraction systems.

Recently, we introduced a new approach to the separation of mixtures of REEs by replacing the aqueous phase by a nonaqueous phase. ${ }^{24}$ In particular, it was shown that REEs can be extracted from a polar phase containing ethylene glycol, lithium nitrate and REE nitrates to a less polar phase consisting of Cyanex 923 diluted in $n$-dodecane. Cyanex 923 is a commercial mixture of trialkylphosphine oxides, ${ }^{25}$ and it has often been used for solvent extraction of REEs. ${ }^{26-29}$ The extraction of REE nitrates from ethylene glycol $\left(+\mathrm{LiNO}_{3}\right)$ was different from the extraction of these salts from aqueous solutions, in the sense that the separation factors between light rare-earth elements (LREEs) and heavy rare-earth elements (HREEs) were much larger in the ethylene glycol system. Non-aqueous solvent extraction with two immiscible organic phases is an experimental technique in the field of solvometallurgy, a branch of extractive metallurgy that is analogous to hydrometallurgy, but using organic solvents instead of water. ${ }^{30}$ Non-aqueous solvent extraction with two immiscible organic phases can offer some advantages compared to extraction from aqueous solutions. For instance, the distribution coefficients are often different from those for extraction from water, and this can lead to enhanced selectivities for separation of mixtures of metals ions. Nonaqueous solvent extraction can also be used for the extraction of metal compounds that are sensitive to water.

In this paper, we describe how REEs can efficiently be extracted and separated from an ethylene glycol solution containing lithium chloride and REE chlorides by Cyanex 923 in $n$ dodecane. This type of REE separation is not possible from aqueous solutions because the separation factors for extraction of REEs from aqueous chloride feed solutions by Cyanex 923 are very low. The new extraction system is very suitable for extraction of scandium and for separation of scandium from the other REEs, and for separation of HREEs from LREEs.

\section{Experimental}

\section{Materials and reagents}

$\mathrm{LaCl}_{3} \cdot 7 \mathrm{H}_{2} \mathrm{O}(99.9 \%), \mathrm{CeCl}_{3} \cdot 7 \mathrm{H}_{2} \mathrm{O}(99.9 \%)$ and $\mathrm{GdCl}_{3} \cdot 6 \mathrm{H}_{2} \mathrm{O}$ (99.9\%) were purchased from Alfa Aesar (Ward Hill, USA), $\mathrm{PrCl}_{3} \cdot 7 \mathrm{H}_{2} \mathrm{O}$ (99.9\%), $\mathrm{NdCl}_{3} \cdot 6 \mathrm{H}_{2} \mathrm{O}$ (99.9\%), $\mathrm{YCl}_{3} \cdot 6 \mathrm{H}_{2} \mathrm{O}(99.9 \%)$, $\mathrm{YbCl}_{3} \cdot 6 \mathrm{H}_{2} \mathrm{O}(99.9 \%)$ from Strem Chemicals (Newburyport, USA) and $\mathrm{DyCl}_{3} \cdot 6 \mathrm{H}_{2} \mathrm{O}$ (99.9\%) from abcr $\mathrm{GmbH}$ (Karlsruhe, Germany). $\mathrm{Sc}_{2} \mathrm{O}_{3}$ was kindly supplied by Solvay (La Rochelle, France). $\mathrm{ScCl}_{3} \cdot x \mathrm{H}_{2} \mathrm{O}$ was prepared from $\mathrm{Sc}_{2} \mathrm{O}_{3}$ following a reported method. ${ }^{31}$ Ethylene glycol (99.9\%), n-dodecane (>99\%), 1-decanol (98\%), $N, N$-dimethylformamide (99\%), methanol $(>99.9 \%)$, lactic acid $\left(90 \%\right.$ in $\left.\mathrm{H}_{2} \mathrm{O}\right)$, citric acid $(99 \%)$ and methanesulfonic acid (98\%) were obtained from Acros Organics (Geel, Belgium). Sodium chloride ( $>99 \%$ ) was obtained from
Fisher Scientific (Geel, Belgium), ammonium chloride (99\%), anhydrous calcium chloride (95\%) from Chem-Lab NV (Zedelgem, Belgium), anhydrous magnesium chloride (99\%) from Alfa Aesar (Ward Hill, USA) and lithium chloride (99.9\%) from Sigma-Aldrich (Diegem, Belgium). $\mathrm{HCl}(\sim 37 \%)$ and dimethyl sulfoxide $(100 \%)$ were supplied by VWR Chemicals (Haasrode, Belgium). Trihexyl(tetradecyl)phosphonium chloride (Cyphos® IL 101, >97\%), Cyanex® 923 and bis(2,4,4-dimethylpentyl) phosphinic acid (Cyanex® 272) were provided by Cytec Industries (Canada). Tricaprylmethylammonium chloride (Aliquat ${ }^{\circledR}$ 336, 88.2-90.6\%) was purchased from Sigma-Aldrich (Diegem, Belgium). Trioctylphosphine oxide (TOPO, 99\%) and bis(2ethylhexyl)amine (99\%) were obtained from Acros Organics (Geel, Belgium). The silicone solution in isopropanol for the treatment of the TXRF quartz glass carriers was obtained from SERVA Electrophoresis GmbH (Heidelberg, Germany). The gallium standard (1000 $\mathrm{mg} \mathrm{L}^{-1}$ in $2-5 \% \mathrm{HNO}_{3}$ ) was purchased from Chem-Lab NV (Zedelgem, Belgium). All chemicals were used as received without any further purification.

\section{Instrumentation}

A flat magnetic stirrer (MIX 15 eco model, 2mag magnetic emotion) was used to mix the two phases in the solvent extraction experiments. The metal concentration in the ethylene glycol phase was determined by a total reflection X-ray fluorescence (TXRF) spectrometer (Bruker S2 Picofox). ${ }^{1} \mathrm{H}$ NMR spectra were recorded on a Bruker Avance 300 spectrometer (operating at $300 \mathrm{MHz}$ ) and the ${ }^{31} \mathrm{P}$ NMR spectra on a Bruker Ascend 400 spectrometer (operating at $162 \mathrm{MHz}$ ). The samples for NMR spectra were prepared in acetone- $d_{6}$. The chemical shifts are noted in parts per million ( $\mathrm{ppm})$, referenced to tetramethylsilane for ${ }^{1} \mathrm{H}$ and to $85 \% \mathrm{H}_{3} \mathrm{PO}_{4}$ (external reference) for ${ }^{31} \mathrm{P}$ NMR. The water content was determined by coulometric Karl Fischer titration (Mettler-Toledo DL39 titrator). The viscosity of ethylene glycol was measured using an Anton Paar rolling-ball viscometer (Lovis $2000 \mathrm{ME}$ ). The concentration of ethylene glycol in $n$-dodecane samples was determined using a gas chromatograph, combined with a flame ionization detector (GC-FID) and a Turbomatrix 16 headspace autosampler (HS) (Perkin Elmer, USA). A Perkin Elmer CP-SIL 8 CB (5\%-phenyl-95\%-dimethylpolysiloxane) capillary column, $50 \mathrm{~m}$ long, $0.32 \mathrm{~mm}$ I.D. and $1.20 \mu \mathrm{m}$ film thickness was used as GC column. The PE TotalChrom Version 6.3.2.0646 software package was used to determine the peak areas in the gas chromatogram.

\section{EXAFS measurement}

Extended X-ray Absorption Fine Structure (EXAFS) spectra of the $\mathrm{L}_{\mathrm{III}}$ edge of ytterbium (8944 eV) were measured at the DutchBelgian Beamline (DUBBLE, BM26A) of the European Synchrotron Radiation Facility (ESRF) in Grenoble (France). The energy of the X-ray beam was tuned by a double-crystal monochromator operating in fixed-exit mode using a $\mathrm{Si}(111)$ crystal pair. The measurements were done in transmission mode using $\mathrm{Ar} / \mathrm{He}$ gas filled ionization chambers at ambient pressure. A brass sample holder with Kapton ${ }^{\circledR}$ windows was used together 
with a flexible polymeric spacer (VITON $®)$ with a thickness of $0.4 \mathrm{~mm}$.

Standard procedures were used for pre-edge subtraction and data normalization in order to isolate the EXAFS function $(\chi)$. The isolated EXAFS oscillations, accomplished by a smoothing spline as realized in the software package Viper, ${ }^{32}$ were $k^{4}-$ weighted and Fourier-transformed over the $k$-range from 2.35 to $14.08 \AA^{-1}$ with a Gaussian round end windowing function. The data were fitted using the ab initio code FEFF $7.02,{ }^{33}$ which was used to calculate the theoretical phase and amplitude functions that subsequently were used in the non-linear least-squares refinement of the experimental data. Fitting of the model was performed in $R$ space between 0.0 and $3.4 \AA$ in case of ytterbium in ethylene glycol and between 0.0 and $3.5 \AA$ for ytterbium extracted by Cyanex 923. $S_{0}$ was fixed at 0.9 for ytterbium in ethylene glycol and 0.95 for ytterbium extracted by Cyanex 923 .

\section{Solvent extraction procedure}

Non-aqueous solvent extraction experiments were carried out by mixing equal volumes of the more polar organic phase (REEs in ethylene glycol $+\mathrm{LiCl}$ ) and the less polar organic phase (Cyanex 923 in $n$-dodecane) in glass vials at $1000 \mathrm{rpm}$ and room temperature (RT, $293 \pm 2 \mathrm{~K}$ ) for $15 \mathrm{~min}$. An aqueous solution and Cyanex 923 in $n$-dodecane were the two phases for the conventional solvent extraction experiments. The behavior of the diluents $n$-dodecane and kerosene is very similar. Kerosene is a mixture of hydrocarbons ( $\mathrm{C}_{10}$ to $\mathrm{C}_{16}$ compounds) and it is widely used in industry as a diluent for solvent extraction processes. The pure compound $n$-dodecane is often used for fundamental solvent extraction studies, because it is more convenient for characterization studies with for instance NMR or GC-FID. 1-Decanol was added to Cyanex 923/n-dodecane as phase modifier both non-aqueous and conventional solvent extraction experiments. After equilibrium, the concentrations of the REEs in ethylene glycol were determined by TXRF after proper dilutions and addition of a gallium internal standard. ${ }^{34}$ The concentrations of the REEs in the $n$-dodecane phase were calculated via the mass balance. The quartz glass sample carriers for TXRF measurements were pretreated with $20 \mu \mathrm{L}$ of a silicone solution in isopropanol, dried in oven for $2 \mathrm{~min}$ at $333 \mathrm{~K}$ followed by addition of $2 \mu \mathrm{L}$ sample to carrier and dried at $333 \mathrm{~K}$ for $30 \mathrm{~min}$. The samples were measured for $300 \mathrm{~s}$ in the TXRF spectrometer. All samples were measured in duplicate.

The distribution ratio $D$ is defined as the ratio of total metal concentration in the less polar organic phase ( $n$-dodecane, $c_{\mathrm{DD}}$ ) to the total concentration in more polar organic phase (ethylene glycol, $c_{\mathrm{EG}}$ ) at equilibrium:

$$
D=\frac{c_{\mathrm{DD}}}{c_{\mathrm{EG}}}
$$

For the separation of two metals $\mathrm{M}_{\mathrm{A}}$ and $\mathrm{M}_{\mathrm{B}}$, a separation factor $\beta$ can be defined:

$$
\beta_{\mathrm{A}, \mathrm{B}}=\frac{D_{\mathrm{A}}}{D_{\mathrm{B}}}
$$

where $D_{\mathrm{A}} \geq D_{\mathrm{B}}$.
The percentage extraction $\% E$ is calculated as follows:

$$
\% E=\frac{D}{\frac{V_{\mathrm{EG}}}{V_{\mathrm{DD}}}+D} \times 100
$$

where $V_{\mathrm{EG}}$ is the volume of the ethylene glycol phase and $V_{\mathrm{DD}}$ is the volume of the $n$-dodecane/Cyanex 923 phase.

The composition of the feed was about $5 \mathrm{~g} \mathrm{~L}^{-1}$ of each REE ion (Sc(III), La(III), Ce(III), Pr(III), Nd(III), Gd(III), Dy(III), Y(III), Yb(III)) in ethylene glycol $(+\mathrm{LiCl})$ for most of the experiments, unless otherwise specified and about $2.5 \mathrm{~g} \mathrm{~L}^{-1}$ for experiments of screening of extractants, addition of polar solvents $(50 \%(\mathrm{v} / \mathrm{v}))$ and complexing agents. The accurate concentrations in the solution has been measured by TXRF.

\section{Results and discussion}

\section{Mutual solubility of organic phases}

Since two organic phases are being used for the solvent extraction of REEs, it is important to determine their mutual solubility. Mutual solubility experiments were conducted by mixing equal volumes of ethylene glycol and Cyanex 923/ndodecane as a function of the $\mathrm{LiCl}$ concentration, feed concentration and extractant concentration. The solubility of Cyanex 923 in ethylene glycol phase was determined by ${ }^{31} \mathrm{P}$ NMR and the solubility/co-extraction of ethylene glycol in Cyanex 923/ $n$-dodecane was measured by gas chromatography. In our previous work, it was found that ethylene glycol and $n$-dodecane form two mutually immiscible phases. ${ }^{24}$ The solubility of Cyanex 923/n-dodecane in the ethylene glycol phase is very low, as shown by the absence of resonance lines corresponding to $\mathrm{P}=\mathrm{O}$ in the ${ }^{31} \mathrm{P}$ NMR spectra. The solubility/co-extraction of ethylene glycol by 1 M Cyanex 923 (+10\% v/v 1-decanol)/n-dodecane was measured to be $46.3 \mathrm{~g} \mathrm{~L}^{-1}$ from the gas chromatography measurements. The addition of $2 \mathrm{M} \mathrm{LiCl}$ to the ethylene glycol phase suppressed the solubility/co-extraction of ethylene glycol to $29.7 \mathrm{~g} \mathrm{~L}^{-1}$. The solubility of ethylene glycol in $1 \mathrm{M}$ Cyanex 923 $(+10 \% \mathrm{v} / \mathrm{v} 1$-decanol $) / n$-dodecane was further suppressed to $23.5 \mathrm{~g} \mathrm{~L} \mathrm{~L}^{-1}$ when extractions were carried out from a feed solution of $50 \mathrm{~g} \mathrm{~L}^{-1}$ of REEs together with $2 \mathrm{M} \mathrm{LiCl}$. Additionally, an experiment was carried out to compare the extraction of water molecules by Cyanex 923 from aqueous solutions with the extraction of ethylene glycol by Cyanex 923 from ethylene glycol solutions. The co-extraction of water molecules by $1 \mathrm{M}$ Cyanex $923(+10 \% \mathrm{v} / \mathrm{v}$ 1-decanol $) / n$-dodecane as determined by Karl Fischer titration was $24.6 \mathrm{~g} \mathrm{~L}^{-1}$ after equilibrating with distilled water and was suppressed to $22.7 \mathrm{~g} \mathrm{~L}^{-1}$ from aqueous solutions containing $2 \mathrm{M} \mathrm{LiCl}$. The co-extraction of water was even further reduced to $21.7 \mathrm{~g} \mathrm{~L}^{-1}$ from the aqueous feed solution containing $\sim 50 \mathrm{~g} \mathrm{~L}^{-1}$ of REEs. The co-extraction of water and ethylene glycol are comparable.

The viscosity of the ethylene glycol was measured as a function of $\mathrm{LiCl}$ concentration at $298 \mathrm{~K}$ (Table S1 $\dagger$ ). The viscosity of the ethylene glycol phase gradually increased from $18 \mathrm{mPa}$ s for $0 \mathrm{M} \mathrm{LiCl}$ to $211 \mathrm{mPa}$ s for $4 \mathrm{M} \mathrm{LiCl}$. Similarly, the viscosity of the ethylene glycol feed (containing $\sim 45 \mathrm{~g} \mathrm{~L}^{-1}$ of REE) increased from $30 \mathrm{mPa} s$ for $0 \mathrm{M} \mathrm{LiCl}$ to $308 \mathrm{mPa} \mathrm{s}$ for $4 \mathrm{M} \mathrm{LiCl}$. An 
increase in temperature resulted in suppression of viscosity from $124 \mathrm{mPa}$ s at $293 \mathrm{~K}$ to $21 \mathrm{mPa}$ s at $333 \mathrm{~K}$ for ethylene glycol feed containing $\sim 45 \mathrm{~g} \mathrm{~L}^{-1}$ of REE and $2 \mathrm{M} \mathrm{LiCl}$ (Table S2 $\dagger$ ).

\section{Screening of extractants}

In order to find a suitable extractant for the separation of REEs from non-aqueous ethylene glycol (+2 M LiCl) solutions containing 9 REE ions (Sc(III), La(III), Ce(III), Pr(III), Nd(III), Gd(III), Dy(III), Y(III) and $\mathrm{Yb}(\mathrm{III})$ ) each of a concentration of $\sim 2.5 \mathrm{~g} \mathrm{~L}^{-1}$, a screening experiment was carried out using acidic, neutral and basic extractants. The extractants tested were Cyanex 272, Cyanex 923, trioctylphosphine oxide (TOPO), bis(2-ethylhexyl) amine, Cyphos IL 101 and Aliquat 336 (Fig. 1). All extractants were dissolved in $n$-dodecane diluent. Preliminary experiments showed that the phase separation was not good. Therefore, $10 \%$ (v/v) 1-decanol was added to $n$-dodecane as phase modifier. In order to determine the extraction behavior of $10 \%(\mathrm{v} / \mathrm{v}) 1$-decanol $/ n$-dodecane diluent, one extraction experiment was carried out with $10 \%(\mathrm{v} / \mathrm{v}) 1$-decanol $/ n$-dodecane diluent without Cyanex 923 added to the diluent phase. It was found that the extraction of all REEs was close to zero. This shows that $10 \%$ (v/ v) 1-decanol acts only as phase modifier and plays no role as extractant. The concentration of each extractant was varied from $0.1 \mathrm{M}$ to $1 \mathrm{M}$, except for TOPO, for which the maximum concentration that could be obtained was $0.5 \mathrm{M}$.

$\mathrm{Sc}(\mathrm{III})$ has a strong affinity for Cyanex 923 and TOPO, resulting in high extraction efficiencies (Fig. 2 and 3). The extraction percentages were higher for Cyanex 923 than for TOPO. The order of extraction of REEs using these phosphine oxide reagents is: $\mathrm{Sc}$ (III) $>\mathrm{Yb}$ (III) $>\mathrm{Y}$ (III) $>$ Dy(III) $>\mathrm{Gd}$ (III) $>\mathrm{Nd}$ (III) $>$ $\operatorname{Pr}($ III) $>\mathrm{Ce}($ III) $>\mathrm{La}$ (III). The extraction behavior of $\mathrm{Y}$ (III) was

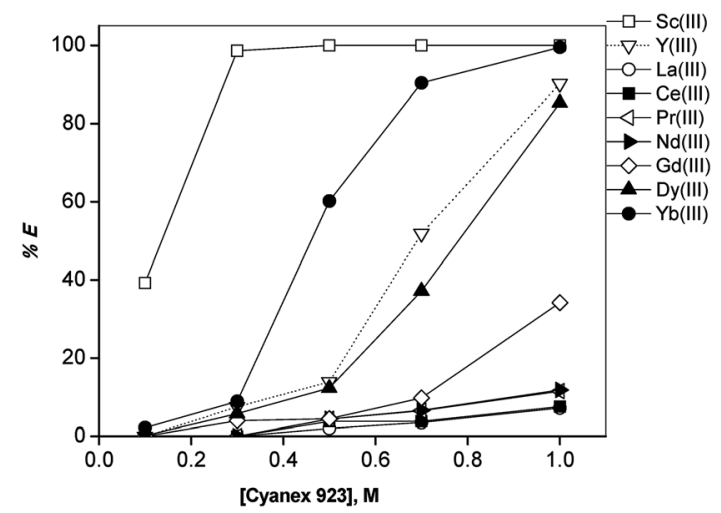

Fig. 2 Influence of the Cyanex 923 concentration on the solvent extraction of REEs. Experimental conditions: [REE(III)]: $\sim 2.5 \mathrm{~g} \mathrm{~L}^{-1}$ (each), [LiCl]: 2 M, [Cyanex 923]: 0.1-1 M in $n$-dodecane with 10\% (v/v) 1-decanol.

similar to that of the HREEs, in between $\mathrm{Yb}$ (III) and Dy(III). It was observed that the extractants Cyphos IL 101, Aliquat 336 and bis(2-ethylhexyl)amine were unable to extract REEs from ethylene glycol $(+\mathrm{LiCl})$ solutions under the experimental conditions tested. $\mathrm{Sc}(\mathrm{III})$ was selectively extracted and negligible extraction (\% $E=0-5 \%$ ) of all other REEs was observed for Cyanex 272 (Fig. 4).

\section{Comparison of extraction from non-aqueous and aqueous solutions}

Solvent extraction of a mixture of REEs including $\mathrm{Sc}$ (III) (each $\left.\sim 5 \mathrm{~g} \mathrm{~L}^{-1}\right)$ has been carried out from ethylene glycol $(+\mathrm{LiCl})$ and

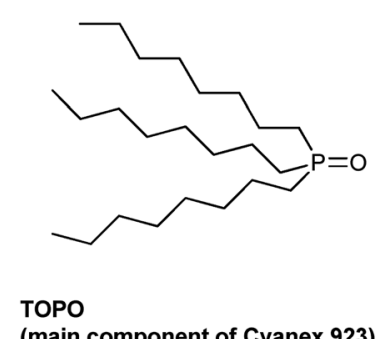

(main component of Cyanex 923)

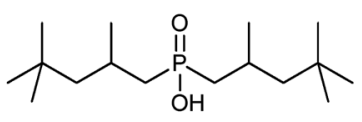

Cyanex 272

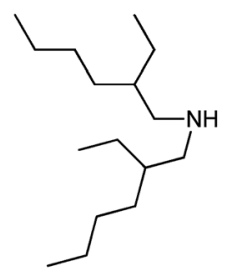

bis(2-ethylhexyl)amine
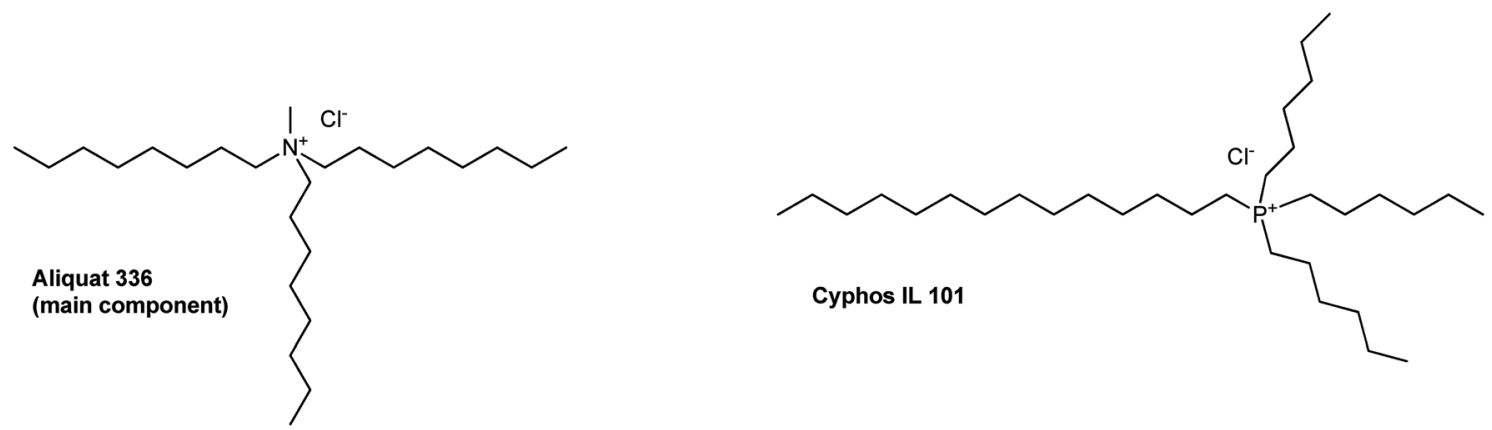

Fig. 1 Structures of Cyanex 923, Cyanex 272, bis(2-ethylhexyl)amine, Aliquat 336 and Cyphos IL 101. For Cyanex 923, the main component trioctylphosphine oxide (TOPO) is shown. Other components include $\mathrm{R}_{2} \mathrm{R}^{\prime} \mathrm{P}=\mathrm{O}, \mathrm{RR}_{2}{ }_{2} \mathrm{P}=\mathrm{O}$ and $\mathrm{R}_{3}^{\prime} \mathrm{P}=\mathrm{O}\left(\mathrm{R}=\right.$ octyl, $\mathrm{R}^{\prime}=$ hexyl). For $\mathrm{Aliquat} 336$, the main component methyltrioctylammonium chloride is shown. 


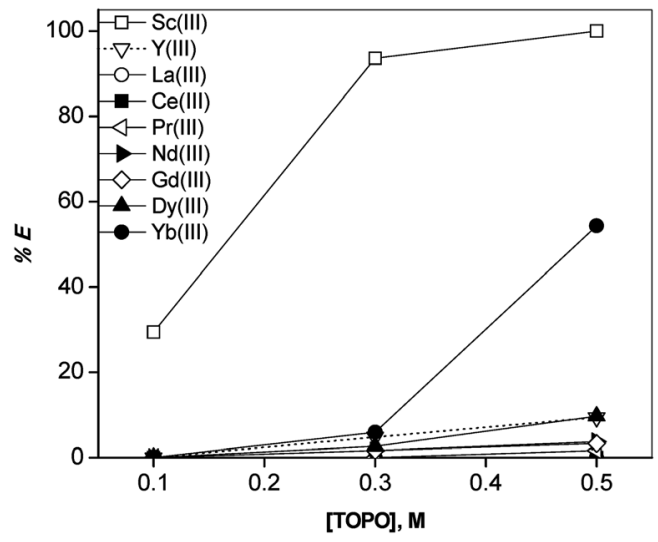

Fig. 3 Influence of the TOPO concentration on the solvent extraction of REEs. Experimental conditions: [REE(III)]: $\sim 2.5 \mathrm{~g} \mathrm{~L}^{-1}$ (each), [LiCl]: $2 \mathrm{M}$, [TOPO]: 0.1-0.5 M in $n$-dodecane with 10\% (v/v) 1-decanol.

aqueous chloride solutions using Cyanex 923 dissolved in n-dodecane (Fig. 5). Sc(III) was selectively extracted from aqueous chloride solutions at all concentrations, because Cyanex 923 has a strong affinity for Sc(III). The percentage extraction of all other REEs was close to zero, even for 1 M Cyanex 923. Therefore, a mixture of REEs cannot be separated under these conditions. In the case of ethylene glycol solutions, $\mathrm{Sc}(\mathrm{III})$ was selectively extracted at Cyanex 923 concentrations up to $0.5 \mathrm{M}$. It must be noted that $\mathrm{Sc}$ (III) is selectively extracted from both aqueous and ethylene glycol solutions. However, the extraction of $\mathrm{Sc}$ (III) is more efficient from ethylene glycol solutions than from aqueous chloride solutions. Under similar experimental conditions (0.3 M Cyanex 923), the \% $E$ of Sc(III) is $67.7 \%$ from ethylene glycol solutions, where as it is $55.6 \%$ from aqueous chloride solutions. Additionally, only Sc(III) was extracted from aqueous solutions. On the other hand, HREEs such as $\mathrm{Yb}(\mathrm{III}), \mathrm{Y}(\mathrm{III})$ and Dy(III) were also extracted together with Sc(III) from ethylene glycol at Cyanex 923 concentrations higher than $0.5 \mathrm{M}$. For instance, the $\% E$ of $\mathrm{Yb}$ (III) was $91.2 \%$ for ethylene glycol solutions and $0.0 \%$ from aqueous solutions for extraction

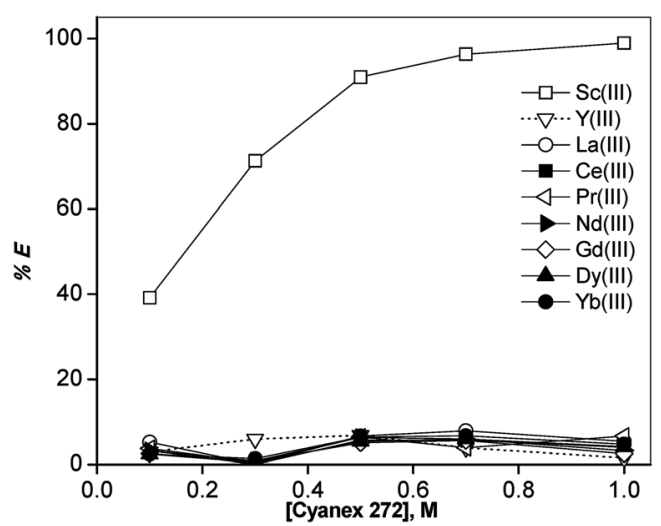

Fig. 4 Influence of the Cyanex 272 concentration on the solvent extraction of REEs. Experimental conditions: [REE(III)]: $\sim 2.5 \mathrm{~g} \mathrm{~L}^{-1}$ (each), [LiCl]: $2 \mathrm{M}$, [Cyanex 272]: 0.1-1 M in $n$-dodecane with $10 \%(\mathrm{v} / \mathrm{v})$ 1-decanol.

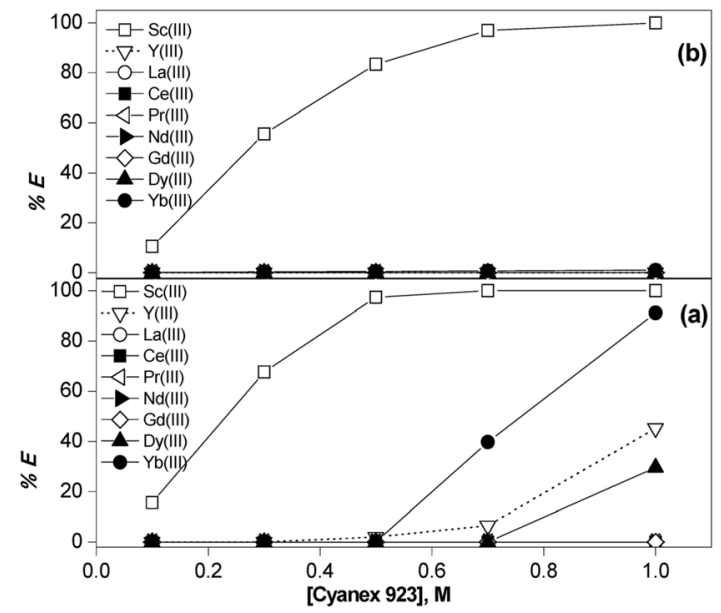

Fig. 5 Influence of the Cyanex 923 concentration on the solvent extraction of a mixture of REEs including Sc(III) from ethylene glycol solutions (a) and from aqueous solutions (b). Experimental conditions: [REE(III)]: $\sim 5 \mathrm{~g} \mathrm{~L}^{-1}$ (each), [LiCl]: $2 \mathrm{M}$, [Cyanex 923]: 0.1-1 $\mathrm{M}$ in $n$-dodecane with $10 \%(\mathrm{v} / \mathrm{v})$ 1-decanol.

with 1 M Cyanex 923. This clearly shows that the extraction of HREEs is much more efficient from ethylene glycol solutions than from aqueous solutions. Negligible extraction percentages were found for the LREEs ( $\mathrm{La}, \mathrm{Ce}, \mathrm{Pr}, \mathrm{Nd}$ ) from ethylene glycol solutions as well. These results for extraction from chloride solutions are in good agreement with our previous results for REE extraction from nitrate solutions, where the extraction of the HREEs was more efficient than extraction of the LREEs from ethylene glycol $\left(+\mathrm{LiNO}_{3}\right)$ when compared to aqueous nitrate solutions. ${ }^{24}$

Solvent extraction of rare earths from aqueous chloride solutions by neutral or solvating extractants like Cyanex 923 is inefficient since Cyanex 923 usually transfers metal ions coordinated to their anions (salt extraction). ${ }^{35-37}$ It is well known that rare-earth ions are strongly hydrated in aqueous solutions (with eight or nine coordinated water molecules) and no chloride ion is present in the inner coordination sphere, even at very high chloride concentrations. ${ }^{38,39}$ Due to the lack of coordinating chloride anions, the extraction of rare earths by Cyanex 923 from aqueous chloride solutions is inefficient. For extraction by Cyanex 923, the solvating molecules around the rare-earth ions must be replaced fully or partly by the Cyanex 923 molecules to form adducts. In the case of ethylene glycol (+LiCl) solutions, the rare-earth ions are solvated by ethylene glycol molecules, even though some water molecules can still be present if no anhydrous rare-earth salts are being used. The solvation energy required to remove the solvation sphere around the metal ion in ethylene glycol solutions is lower than the energy required for the removal of the hydration sphere around the metal ion in aqueous solutions. Therefore, the extraction of rare-earth ions by Cyanex 923 from ethylene glycol $(+\mathrm{LiCl})$ is more efficient than the extraction from aqueous chloride solutions. It is also important to note that the difference in extraction behaviour of rare earths from ethylene glycol and aqueous solutions depends on the type of rare-earth ion (LREE or HREE) and coordinating 
anion. For instance, in our previous work we reported that the extraction of the HREEs was more efficient than extraction of the LREEs from ethylene glycol $\left(+\mathrm{LiNO}_{3}\right)$ when compared to aqueous nitrate solutions. ${ }^{24}$

Because Cyanex 923 has a strong affinity for Sc(III), it is relevant to investigate how the extraction behavior changes after the removal of $\mathrm{Sc}(\mathrm{III})$ from aqueous and non-aqueous solutions. Experiments were carried out with a Sc(III)-free feed solution in order to investigate the extraction behavior of REEs after removal of $\mathrm{Sc}$ (III) (Fig. 6). It can be seen that the extraction of the REEs is almost the same for aqueous chloride solutions with and without Sc(III) present in the feed solution. There is no significant extraction of the REEs, with the exception of $\mathrm{Yb}$ (III). The extraction of the HREEs was much more efficient than the extraction of LREEs from ethylene glycol solutions. This makes it possible to separate HREEs efficiently from LREEs. A high separation factor of 191 was obtained for the HREE group $(\mathrm{Yb}+$ $\left.\mathrm{Y}+\mathrm{Dy}, D_{\mathrm{Yb}+\mathrm{Y}+\mathrm{Dy}}=7.63\right)$ over the LREE group $(\mathrm{La}+\mathrm{Ce}+\mathrm{Pr}+\mathrm{Nd}$, $\left.D_{\mathrm{La}+\mathrm{Ce}+\mathrm{Pr}+\mathrm{Nd}}=0.04\right)$ at $1 \mathrm{M}$ Cyanex 923. Fig. 6a also shows that there is a possibility to separate $\mathrm{Yb}$ (III) from rest of the REEs by extraction with $0.3 \mathrm{M}$ or 0.5 M Cyanex 923. This can be evaluated in terms of separation factors. The separation factors for $\mathrm{Yb}$ over Dy + Y are 9.5 at 0.3 M Cyanex 923 and 11.2 at 0.5 M Cyanex 923. These separation factors are sufficiently high to design separation processes for HREEs based on extraction of REE chlorides from ethylene glycol by Cyanex 923. On the other hand, the REEs cannot be separated by extraction with Cyanex 923 from aqueous chloride solutions. Therefore, it can be concluded that replacement of water by ethylene glycol not only enhances the distribution ratios but also the separation factors.

\section{Effect of chloride concentration}

The influence of the chloride concentration on the extraction of REEs ( $\sim 5 \mathrm{~g} \mathrm{~L}^{-1}$ (each)) was studied by increasing the LiCl

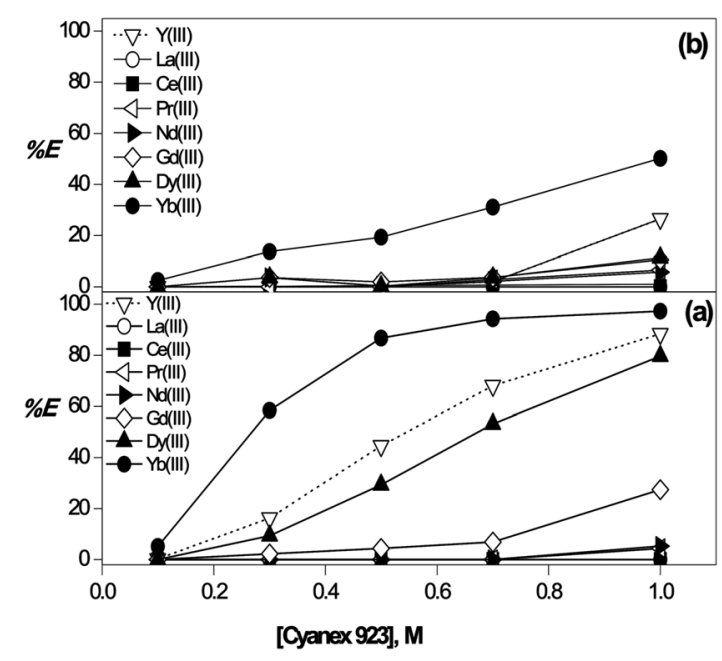

Fig. 6 Influence of the Cyanex 923 concentration on the solvent extraction of a mixture of REEs excluding Sc(III) from ethylene glycol solutions (a) and from aqueous solutions (b). Experimental conditions: [REE(II)]: $\sim 5 \mathrm{~g} \mathrm{~L}^{-1}$ (each), [LiCl]: $2 \mathrm{M}$, [Cyanex 923]: 0.1-1 $\mathrm{M}$ in $n$-dodecane with 10\% (v/v) 1-decanol. concentration from $0.1 \mathrm{M}$ to $4 \mathrm{M}$, with $1 \mathrm{M}$ Cyanex 923 in $n$-dodecane as the extracting solvent (Fig. 7). It can be seen that the extraction of the REEs increases with an increase in $\mathrm{LiCl}$ concentration, which is a typical behavior for solvating extractants. It was observed that $\mathrm{Sc}$ (III) is extracted quantitatively, even at very low chloride concentrations. The separation factors for $\mathrm{Yb}$ over $\mathrm{Dy}+\mathrm{Y}$ are 8.5 for $1 \mathrm{M} \mathrm{LiCl}$ and 9.2 for $2 \mathrm{M}$ LiCl. For the least extractable elements (LREEs), the extraction efficiency was increased to $20 \%$ at high chloride concentrations. High chloride concentrations are not a favorable condition for the separation of REEs. It is clear that by carefully controlling the concentrations of LiCl and Cyanex 923, a mixture of REEs including Sc(III) can be separated conveniently into three or four fractions. One option is to separate Sc(III) from the other REE ions at low chloride concentrations, followed by separation of $\mathrm{Yb}$ (III) and then separation of $\mathrm{Y}$ (III) and Dy(III). All LREEs remain in the ethylene glycol phase. In the second option, after the removal of Sc(III), the HREEs (Yb, Y, Dy) can be separated as a group from other REEs. Therefore the selection of a suitable process depends on the actual composition of the feed solution.

\section{Effect of source of chloride}

The influence of source of the chloride on the separation of REEs ( $\sim 5 \mathrm{~g} \mathrm{~L}^{-1}$ (each)) by using different chloride sources such as $\mathrm{LiCl}, \mathrm{NaCl}, \mathrm{NH}_{4} \mathrm{Cl}(1 \mathrm{M})$ and $\mathrm{MgCl}_{2}, \mathrm{CaCl}_{2}(0.5 \mathrm{M})$ was investigated for $1 \mathrm{M}$ Cyanex 923. The solubility of $\mathrm{LiCl}$ in ethylene glycol is higher than that of any other salt studied. It is possible to dissolve more than $4 \mathrm{M}$ of $\mathrm{LiCl}$ in ethylene glycol, whereas the maximum solubility is $1 \mathrm{M}$ for $\mathrm{NaCl}$ and $\mathrm{NH}_{4} \mathrm{Cl}$, and $0.5 \mathrm{M}$ for $\mathrm{MgCl}_{2}$ and $\mathrm{CaCl}_{2}$. Based on its good solubility in ethylene glycol, LiCl was selected as a source of chloride. Unlike in aqueous solutions, there is no significant salting-out effect for the extraction of REEs (except for $\mathrm{Yb}$ (III)) from ethylene glycol feed solutions. A change of cation of the chloride salt has a negligible effect on the extraction and for on the separation of REEs (Fig. 8).

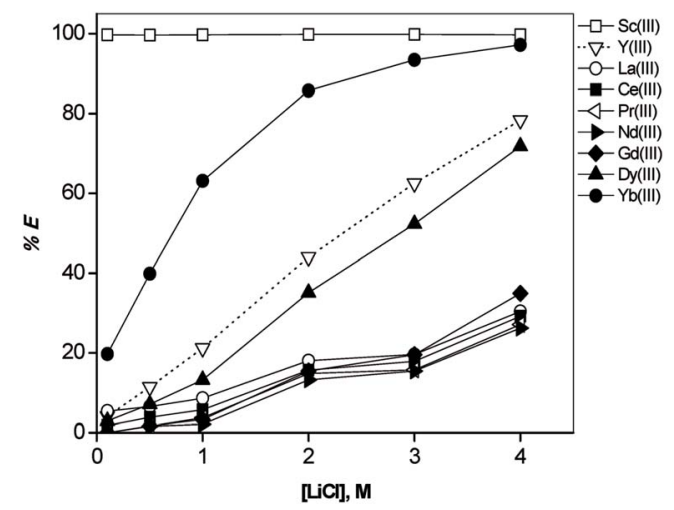

Fig. 7 Influence of the chloride concentration ( $\mathrm{LiCl}$ ) on the solvent extraction of REEs. Experimental conditions: [REE(III)]: $\sim 5 \mathrm{~g} \mathrm{~L}^{-1}$ (each), [LiCl]: 0.1-4 M, [Cyanex 923]: $1 \mathrm{M}$ in $n$-dodecane with 10\% (v/v) 1-decanol. 


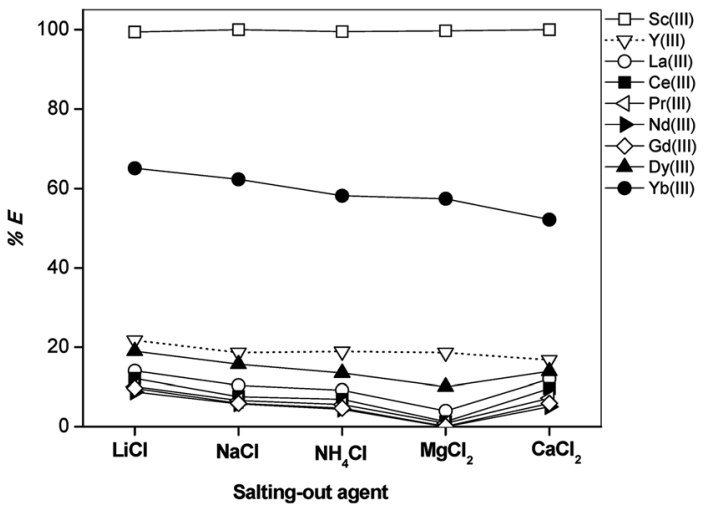

Fig. 8 Influence of the source of chloride ions on the solvent extraction of REEs. Experimental conditions: [REE(III)]: $\sim 5 \mathrm{~g} \mathrm{~L}^{-1}$ (each), $\left[\mathrm{Cl}^{-}\right]=1 \mathrm{M}$, [Cyanex 923]: $1 \mathrm{M}$ in $n$-dodecane with 10\% 1-decanol (v/v).

\section{Addition of a second extractant (synergist) to the less polar organic phase}

Synergistic systems are often used in solvent extraction to study any improvement in the extraction or separation by the addition of a second extractant. ${ }^{4,5}$ Synergistic extraction is generally defined as an enhancement in extraction/separation by the cooperative effect of two extractant molecules in comparison to single extractants. The separation factors may increase by certain combination of extractants. Therefore, experiments were carried out by addition of a second extractant to Cyanex 923: Cyanex 272, TBP or Aliquat 336 (Fig. 9). The total concentration of extractant (Cyanex 923 + other extractant) was kept constant at $1 \mathrm{M}$.

The addition of Cyanex 272 to Cyanex 923 had a positive effect on the extraction of $\mathrm{Yb}(\mathrm{III})$, which means the Cyanex 272 acts as

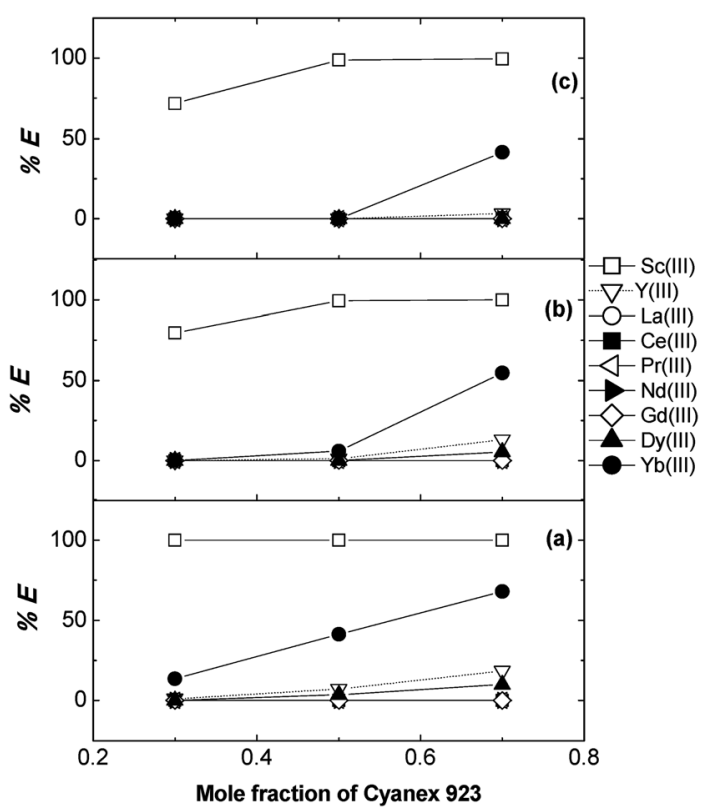

Fig. 9 Solvent extraction of REEs from ethylene glycol (+ $\mathrm{LiCl}$ ) solutions using a mixture of Cyanex 923 and Cyanex 272 (a), TBP (b), Aliquat 336 (c) in $n$-dodecane. Experimental conditions: [REE(III)]: $\sim 5 \mathrm{~g} \mathrm{~L}^{-1}$ (each), [LiCl]: $2 \mathrm{M}$, [Cyanex 923 + other extractant]: $1 \mathrm{M}$. a synergist. On the other hand, addition of TBP or Aliquat 336 to Cyanex 923 had a negative effect on the extraction of $\mathrm{Yb}(\mathrm{III})$, which indicates that these extractants act as an antagonist.

\section{Addition of polar solvents to ethylene glycol}

The influence of addition of the polar solvents water, dimethyl sulfoxide (DMSO), $N, N$-dimethylformamide (DMF) and methanol on the extraction of REEs $\left(\sim 2.5 \mathrm{~g} \mathrm{~L}^{-1}\right.$ (each)) was studied by the addition of $50 \%(\mathrm{v} / \mathrm{v})$ polar solvent to an ethylene glycol feed solution containing $2 \mathrm{M} \mathrm{LiCl}$ (Fig. 10). In mixtures of solvents, ions can be solvated preferentially by one of the solvents in the mixture. The preferential solvation of rare-earth ions can lead to better selectivities for extraction. ${ }^{40}$ It was found that the extraction of $\mathrm{Sc}$ (III) remained unchanged at $100 \%$ extraction in all polar solvents. This shows that Cyanex 923 is a promising candidate to extract $\mathrm{Sc}$ (III) from different non-aqueous solvents. Note that the percentage extraction of $\mathrm{Yb}(\mathrm{III})$ is drastically decreased from $99.5 \%$ to $46.5 \%$ by the addition of $50 \%(\mathrm{v} / \mathrm{v})$ water to ethylene glycol. In other words, the percentage extraction of $\mathrm{Yb}$ (III) increased from $0.0 \%$ in water (Fig. $5 \mathrm{~b}$ ) to $46.5 \%$ in $50 \%$ (v/v) ethylene glycol. There was no significant change in the extraction behavior of $\mathrm{Yb}(\mathrm{III})$ in other solvents (DMSO, DMF and methanol). In the case of DMSO, interesting results were obtained for the extraction of $\mathrm{Y}(\mathrm{III})$ and Dy(III). The $\% E$ was strongly suppressed from $90 \%$ to $25 \%$ for Y(III) and from $85 \%$ to $14 \%$ for Dy(III) when going from ethylene glycol to ethylene glycol/DMSO mixtures. The co-extraction of Y(III) and Dy(III) was suppressed by the addition of DMSO to the ethylene glycol feed solution. The addition of DMSO might be a viable option for the separation of HREEs such as $\mathrm{Yb}$ from Dy $+\mathrm{Y}$. The separation factor of $\mathrm{Yb}$ over $\mathrm{Dy}+\mathrm{Y}$ increased from 26 (in ethylene glycol) to 36 (in DMSO). There is no significant change in extraction behavior upon addition of $50 \%(\mathrm{v} / \mathrm{v})$ DMF or methanol to the ethylene glycol $(+\mathrm{LiCl})$ phase.

\section{Influence of complexing agent}

It was reported that addition of complexing agents like ethylenediaminetetraacetic acid (EDTA), diethylenetriaminepentaacetic

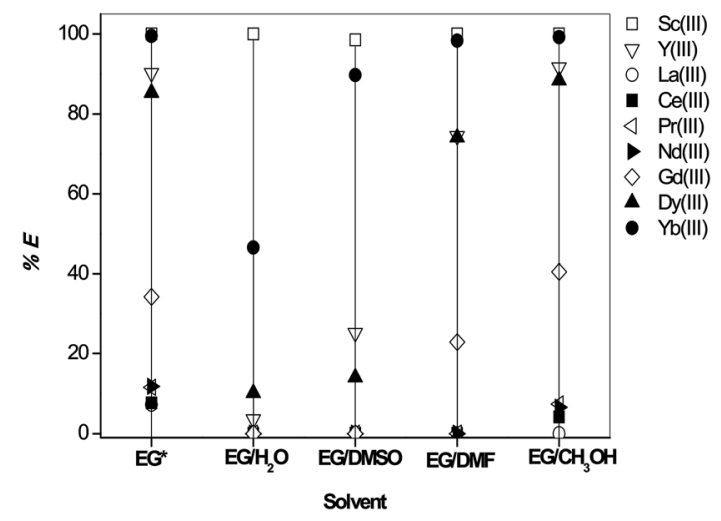

Fig. 10 Influence of addition of polar solvent $(50 \%(\mathrm{v} / \mathrm{v}))$ to ethylene glycol on the solvent extraction of REEs. EG* $=E G$ feed without added polar solvent. Experimental conditions: [REE(III)]: $\sim 2.5 \mathrm{~g} \mathrm{~L}^{-1}$ (each), [LiCl]: 2 M, [Cyanex 923]: $1 \mathrm{M}$ in $n$-dodecane with 10\% (v/v) 1-decanol. 
Table 1 The percentage extraction of REEs from ethylene glycol with complexing agents ${ }^{a}$

\begin{tabular}{lccccrrrr}
\hline$\% E$ & Sc & Y & La & Ce & Pr & Nd & Gd & Dy \\
\hline Citric acid & 99.7 & 1.8 & 0.0 & 0.0 & 0.0 & 0.0 & 0.0 & 0.0 \\
Lactic acid & 99.5 & 0.0 & 0.0 & 0.0 & 0.0 & 0.0 & 0.0 & 0.0 \\
No complexing agent & 100 & 90.2 & 7.2 & 7.6 & 11.5 & 11.8 & 34.2 & 85.3
\end{tabular}

${ }^{a}$ Experimental conditions: [REE(III)]: $\sim 2.5 \mathrm{~g} \mathrm{~L}^{-1}$ (each), [Cyanex 923]: $1 \mathrm{M}$ in $n$-dodecane with 10\% (v/v) 1-decanol.

(DTPA), lactic acid and citric acid to aqueous chloride solutions of rare earths has a positive influence on the separation factors in the solvent extraction with acidic extractants. ${ }^{14,41,42}$ Therefore, we investigated the complexation behaviour of rareearth ions with these complexing agents in ethylene glycol. Unfortunately, EDTA and DTPA did not dissolve in ethylene glycol. The influence of other complexing agents on the extraction and separation of REEs was studied by addition of lactic acid and citric acid $(0.5 \mathrm{M})$ to ethylene glycol solutions containing REE chlorides (Table 1). Sc(III) was still quantitatively extracted, but the percentage extraction of all other REEs, except $\mathrm{Yb}$ (III), was close to zero. The addition of the complexing agents lactic acid and citric acid to the ethylene glycol feed had thus a negative influence on the extraction and separation of REEs. The extraction of some heavy rare earths is suppressed by the addition of EDTA to aqueous chloride solutions. ${ }^{14}$ Further studies are necessary to have a complete insight into effect of complexation on extraction reactions from non-aqueous solutions. This is outside of the scope of the present work.

\section{Stripping and recycling studies}

Stripping studies were carried out for $\mathrm{Yb}$ (III)-loaded $1 \mathrm{M}$ Cyanex 923 (5.3 $\mathrm{g} \mathrm{L}^{-1}$ of $\left.\mathrm{Yb}(\mathrm{III})\right)$ aqueous $\mathrm{HCl}$ and methanesulfonic acid solutions at a volume phase ratio of unity. Stripping percentages were 99.9 and $99.3 \%$ for $1 \mathrm{M}$ methanesulfonic acid and $1 \mathrm{M} \mathrm{HCl}$, respectively. Considering the high stripping percentage for methanesulfonic acid $\left(\mathrm{CH}_{3} \mathrm{SO}_{3} \mathrm{H}\right)$ and the fact that methanesulfonic acid is considered as a sustainable acid and solvent, ${ }^{43}$ methanesulfonic acid was selected for recycling studies (Fig. $\mathrm{S} 1 \dagger$ ). First, $\mathrm{Yb}(\mathrm{III})$ was extracted from the ethylene glycol phase by $1 \mathrm{M}$ Cyanex 923 . The Yb(III)-loaded Cyanex 923/ndodecane phase was stripped with $1 \mathrm{M}$ methanesulfonic acid. In the second cycle, the regenerated Cyanex 923 was used for the extraction of $\mathrm{Yb}(\mathrm{III})$ from ethylene glycol, followed by stripping with $1 \mathrm{M}$ methanesulfonic acid. The system was studied for five cycles and it was found that the percentage extraction (98.5 \pm $1 \%)$ and percentage stripping percentage $(99.8 \pm 1 \%)$ were unaffected.

\section{Conceptual flow sheet}

A conceptual flow sheet is proposed for the group separation of REEs (Fig. 11). First, $\mathrm{Sc}(\mathrm{III})$ is selectively separated by $0.5 \mathrm{M}$ Cyanex 923 from ethylene glycol feed without addition of $\mathrm{LiCl}$, followed by extraction of $\mathrm{Yb}(\mathrm{III})$ using $0.5 \mathrm{M}$ Cyanex 923 from ethylene glycol feed with $2 \mathrm{M} \mathrm{LiCl}$ and Y(III) + Dy(III) using $1 \mathrm{M}$ Cyanex 923 from ethylene glycol feed with $2 \mathrm{M} \mathrm{LiCl}$. Therefore it is possible to fractionate the REEs in to four different groups using one single extractant: $\mathrm{Sc}(\mathrm{III}), \mathrm{Yb}(\mathrm{III}), \mathrm{Y}(\mathrm{III})+\mathrm{Dy}(\mathrm{III})$ and

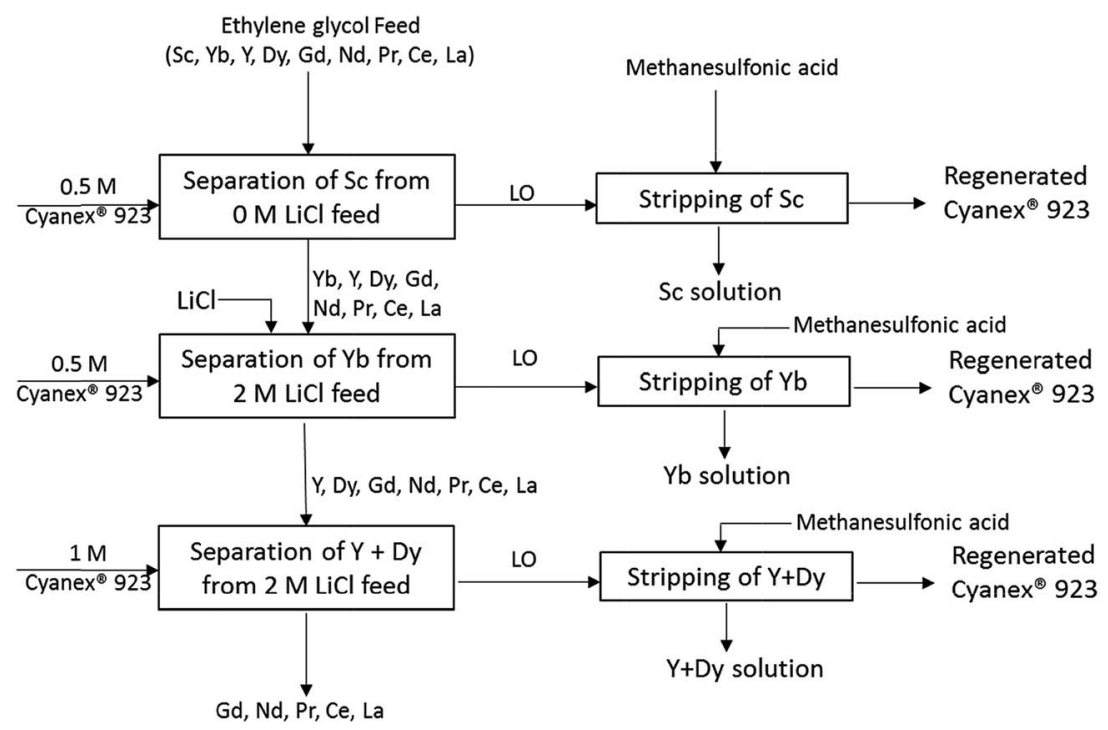

Fig. 11 Conceptual flow sheet for the fractionation of REES from ethylene glycol (+LiCl) feed into four different groups by Cyanex 923 in $n$-dodecane. LO = loaded organic phase. 


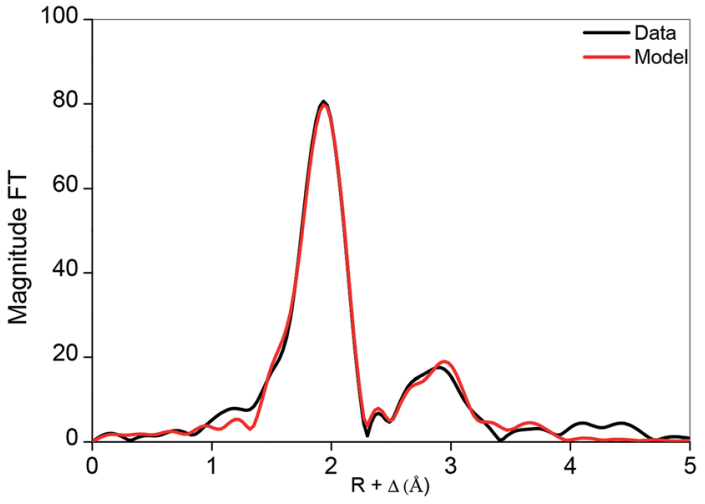

Fig. 12 Fourier transform and fitted model of the EXAFS spectrum of $\mathrm{Yb}(\mathrm{EG})_{4}\left(\mathrm{H}_{2} \mathrm{O}\right)(\mathrm{EG}=$ ethylene glycol$)$.

LREEs. The ethylene glycol raffinate (after complete removal of rare earths) can be recycled back to the feed.

\section{Extraction mechanism and speciation}

The extraction mechanism of REEs was studied by selecting $\mathrm{Yb}$ (III) as a representative REE. EXAFS analysis was used to determine the coordination of $\mathrm{Yb}$ (III) in the ethylene glycol and in the organic phase (Fig. 12-15). The number of oxygen and carbon atoms surrounding $\mathrm{Yb}$ (III) was found to be $9.0(4)$ in ethylene glycol and 8.2(1.2) in the Cyanex 923/n-dodecane, with Debye Waller factors of $0.008(1) \AA^{2}$. The average bond distance between ytterbium and the oxygens atoms was found to be $2.320(1) \AA$. The average bond distance is similar to the average bond length found in the ytterbium aquo complex. ${ }^{44}$ However, all oxygen atoms were found at the same bond distance, which is different from the hydrated ytterbium molecule in which two or three water molecules found at shorter distance than the other water molecules. Any model with oxygens on different positions did not result in a significant better fit (Fig. 12). The carbon atoms were found at 3.302(5) A which corresponds to an $\mathrm{Yb}-\mathrm{O}-\mathrm{C}$ bond angle of approximately $120^{\circ}$. This bond angle is in agreement with the $\mathrm{Yb}-\mathrm{O}-\mathrm{C}$ bond angles between $\mathrm{Yb}$ (III) and a bidentate ethylene glycol molecule found in the crystal

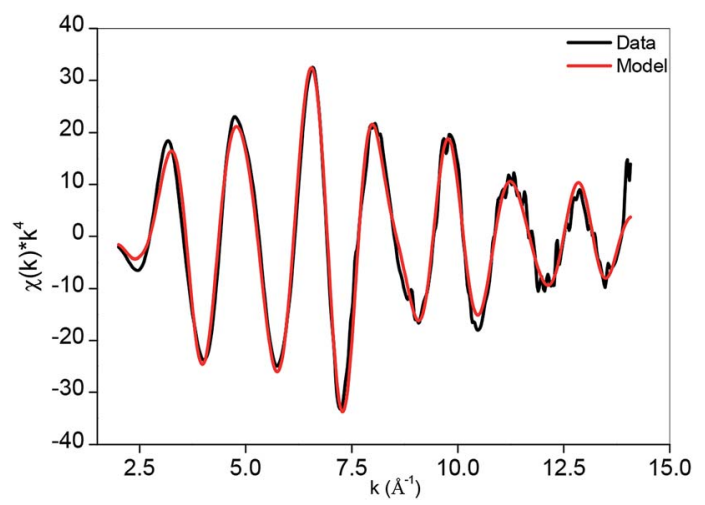

Fig. 13 EXAFS function $\chi(k) \times k^{4}$ and fitted model of $\mathrm{Yb}(\mathrm{EG})_{4}\left(\mathrm{H}_{2} \mathrm{O}\right)$.

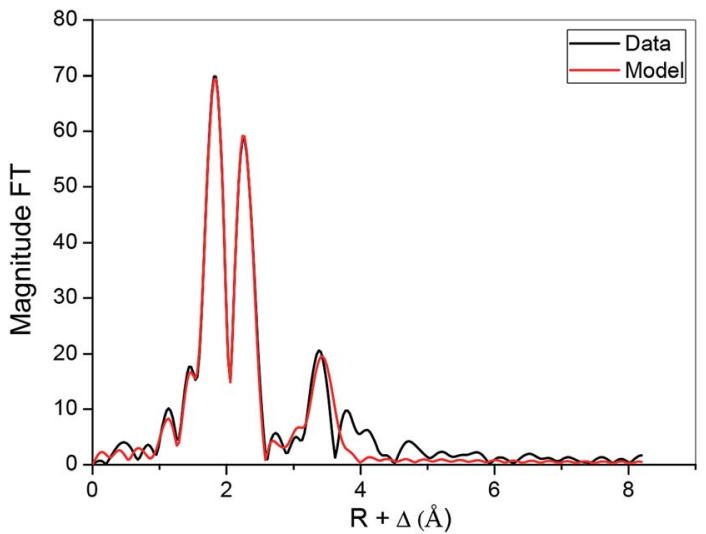

Fig. 14 Fourier transform and fitted model of the EXAFS spectrum of $\mathrm{YbCl}_{3} \cdot 4$ (Cyanex 923).

structure of catena-(tris( $\mu_{4}$-squarato)-bis(ethylene glycol))-diytterbium(III). ${ }^{45}$

The contribution of hydrogen atoms to the EXAFS function (Fig. 13) is very small because of their low atomic mass and large errors can be made on the coordination number. The DebyeWaller factor for hydrogen was constrained to 0.008 to avoid overfitting of the data. Also in this case, 13.7(3.0) hydrogen atoms were found at a distance of 2.735(3) A. From the EXAFS data, it can be concluded that $\mathrm{Yb}$ (III) is surrounded by four bidentate ligating ethylene glycol molecules and maybe one water molecule or one monodentate ligating ethylene glycol molecule. The coordination of $\mathrm{Yb}$ (III) in the ethylene glycol phase (chloride salt of $\mathrm{Yb}(\mathrm{III})$ ) is different from what we previously observed for the coordination of $\mathrm{Nd}$ (III) in ethylene glycol (nitrate salt of $\mathrm{Nd}(\mathrm{III})$ ) and is due to the lower water content of the ethylene glycol phase and the better data quality obtained on the $\mathrm{L}_{\mathrm{III}}$ edge of $\mathrm{Yb}$ in comparison to the $\mathrm{L}_{\mathrm{III}}$ edge of $\mathrm{Nd}^{24}$ The species can be represented by the following reaction, where EG represents ethylene glycol (4):

$$
\mathrm{YbCl}_{3} \cdot 6 \mathrm{H}_{2} \mathrm{O}+4 \mathrm{EG} \leftrightarrow\left[\mathrm{Yb}(\mathrm{EG})_{4} \mathrm{H}_{2} \mathrm{O}\right]^{3+}+3 \mathrm{Cl}^{-}+5 \mathrm{H}_{2} \mathrm{O}
$$

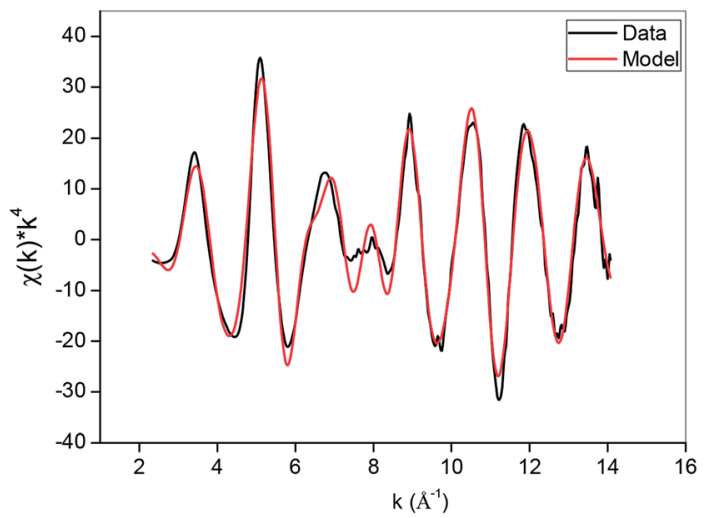

Fig. 15 EXAFS function $\chi(k) \times k^{4}$ and fitted model of $\mathrm{YbCl}_{3} \cdot(4 \mathrm{Cyanex}$ 923). 
Two intense peaks were observed in the Fourier transform of Yb extracted by Cyanex 923 in $n$-dodecane. The second peak is due to the coordination of chlorine atoms (Fig. 14 and 15). The coordination number of the chlorines was optimized by varying $S_{0}$ within a reasonable range. A coordination number of $3.0(1)$, an $S_{0}$ value of 0.95, a bond length of 2.593(2) $\AA$ and a DebyeWaller factor of $0.008(1) \AA^{2}$ were obtained for this path. Fitting the first peak of the Fourier transform resulted in the coordination of 3.9(1) oxygen atoms at an $\mathrm{Yb}-\mathrm{O}$ bond distance of 2.209(1) $\AA$ and with a Debye-Waller factor of 0.004(1) $\AA^{2}$. The $\mathrm{Yb}-\mathrm{O}$ and $\mathrm{Yb}-\mathrm{Cl}$ bond lengths are similar to the bond lengths found in the crystal structure of dichloro-bis(1,1'-bis(diphenylphosphoryl)ferrocene-O, $\mathrm{O}^{\prime}$ )-ytterbium(III) tetrachloro-iron(III). ${ }^{46}$ Notice that in this compound, $\mathrm{Yb}$ (III) is coordinated by only two chloride ions instead of three, but also contains four coordinating phosphine oxide groups. We also tried to fit the third peak in the Fourier transform, which can only be due to the phosphorus atom present in the Cyanex 923 molecule and the almost linear $\mathrm{Yb}-\mathrm{O}-\mathrm{P}$ three- and four-legged scattering paths as there are no other atoms able to contribute at this distance. Unfortunately, any fit, including the two-, three- and four-legged scattering paths resulted in bad fits of this peak which might be due to highly distorted paths lengths. ${ }^{47,48}$ The best fit was obtained by including only the two-legged scattering path Ln-P. This resulted in a coordination number of 4.5(4), a DebyeWaller factor of 0.01(1) $\AA^{2}$ and a path length of 3.788(7) A. Mark that this rather long path length is due to the almost linear Ln-O-P bond angle, which is also found in different crystal structures of lanthanides with phosphine oxides. ${ }^{46,48}$ Moreover, exact bond length is probably lower, as the peak is fitted at slightly higher distance.

To support the speciation study by EXAFS in the Cyanex 923/ $n$-dodecane phase, the dependence of the $\mathrm{Yb}$ (III) distribution ratio on the Cyanex 923 concentration was investigated. Fig. 16 demonstrates the plot of $\log D$ vs. $\log [$ Cyanex 923] is a straight line with a slope of about 4, suggesting the involvement of four molecules of Cyanex 923 in the extracted species. Therefore, slope analysis also gives additional support for the extracted

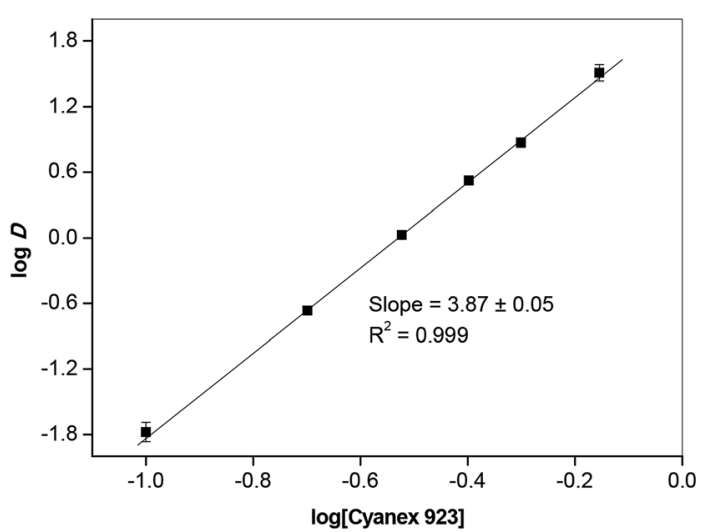

Fig. 16 Influence of the Cyanex 923 concentration on the extraction of $\mathrm{Yb}(\mathrm{III})$ from ethylene glycol $(+\mathrm{LiCl})$ solutions. Experimental conditions: $[\mathrm{Yb}(\mathrm{III})]$ : $5.2 \mathrm{~g} \mathrm{~L}^{-1},[\mathrm{LiCl}]: 2 \mathrm{M}$, [Cyanex 923]: 0.1-0.7 $\mathrm{M}$ in n-dodecane with 10\% (v/v) 1-decanol, time: $30 \mathrm{~min}, \mathrm{RT}$. species. Based on slope analysis and the species in the Cyanex 923/ $n$-dodecane phase by EXAFS data, the following extraction reaction can be proposed:

$$
\left[\mathrm{Yb}(\mathrm{EG})_{4} \mathrm{H}_{2} \mathrm{O}\right]^{3+}+3 \mathrm{Cl}^{-}+4 \overline{\mathrm{L}} \leftrightarrow \overline{\mathrm{YbCl}_{3} \cdot 4 \mathrm{~L}}+4 \mathrm{EG}+\mathrm{H}_{2} \mathrm{O}
$$

where $\mathrm{L}=$ Cyanex 923 and the overbar represents species in Cyanex 923/n-dodecane phase.

\section{Conclusions}

This paper shows that the extraction of REE chlorides from ethylene glycol solutions is significantly different from extraction from aqueous feed solutions. The replacement of water by the organic solvent ethylene glycol allows for the efficient separation of REEs from a chloride feed solution. Cyanex 923 was found to be the best extractant for the separation of REEs from ethylene glycol (+LiCl) solutions. Cyanex 923 has strong affinity for $\mathrm{Sc}(\mathrm{III}), \mathrm{Yb}$ (III) and $\mathrm{Y}(\mathrm{III})$. The addition of LiCl has a positive effect on the percentage extraction. The type of chloride salt has a negligible effect. Cyanex 272 acts as synergist and TBP, Aliquat 336 as antogonists in their mixtures with Cyanex 923 for the extraction of REEs. The addition of the polar solvent DMSO to ethylene glycol $(+\mathrm{LiCl})$ solutions increased the separation factor of $\mathrm{Yb}$ over $\mathrm{Y}+\mathrm{Dy}$. The addition of complexing agents to ethylene glycol phase decreased the extraction of REEs. Quantitative stripping of $\mathrm{Yb}$ (III) could be carried out by $\mathrm{HCl}$ or methanesulfonic acid. The extraction mechanism and extracted species were determined by EXAFS and slope analysis. A conceptual flow sheet was proposed for the separation of REEs into four different groups: $\mathrm{Sc}(\mathrm{III}), \mathrm{Yb}(\mathrm{III}), \mathrm{Y}(\mathrm{III})+\mathrm{Dy}(\mathrm{III})$ and LREEs.

\section{Conflicts of interest}

There are no conflicts of interest to declare.

\section{Acknowledgements}

The research leading to these results received funding from the European Research Council (ERC) under the European Union's Horizon2020 Research and Innovation Programme: Grant Agreement 694078 - Solvometallurgy for critical metals (SOLCRIMET). Cytec Industries (Canada) is acknowledged for a gift of samples of Cyanex® 923 and Cyanex ${ }^{\circledR} 272$. TVH thanks the FWO Flanders for a postdoctoral fellowship.

\section{References}

1 F. Xie, T. A. Zhang, D. Dreisinger and F. Doyle, A critical review on solvent extraction of rare earths from aqueous solutions, Miner. Eng., 2014, 56, 10-28.

2 N. Krishnamurthy and C. Gupta, Extractive Metallurgy of Rare Earths, CRC Press, Boca Raton (Florida), 2nd edn, 2016.

3 J. Lucas, P. Lucas, T. Le Mercier, A. Rollat and W. Davenport, Rare Earths: Science, Technology, Production and Use, Elsevier, Amsterdam, 1st edn, 2014. 
4 G. Ritcey and A. Ashbrook, Solvent extraction: principles and applications to process metallurgy, Volume I, Elsevier, Amsterdam, 1984.

5 G. Ritcey and A. Ashbrook, Solvent extraction: principles and applications to process metallurgy, Volume II, Elsevier, Amsterdam, 1979.

$6 \mathrm{X}$. Sun, S. Meng and D. Li, Studies on the synergistic extraction of rare earths with a combination of 2ethylhexylphosphonic mono-2-ethylhexyl ester and trialkylphosphine oxide, J. Chem. Technol. Biotechnol., 2006, 81, 755-760.

7 X. Sun, J. Wang, D. Li and H. Li, Synergistic extraction of rare earths by mixture of bis(2,4,4-trimethylpentyl)phosphinic acid and Sec-nonylphenoxy acetic acid, Sep. Purif. Technol., 2006, 50, 30-34.

8 B. N. Kumar, B. R. Reddy, M. L. Kantam, J. R. Kumar and J. Y. Lee, Synergistic Solvent Extraction of Neodymium(III) from Chloride Solutions using a Mixture of Triisooctylamine and bis(2,4,4-Trimethylpentyl) Monothiophosphinic Acid, Sep. Sci. Technol., 2014, 49, 130136.

9 M. Reddy, J. Bharathi, S. Peter and T. Ramamohan, Synergistic extraction of rare earths with bis(2,4,4trimethylpentyl)dithiophosphinic acid and trialkyl phosphine oxide, Talanta, 1999, 50, 79-85.

$10 \mathrm{X}$. Wang, M. Du and H. Liu, Synergistic extraction study of samarium(III) from chloride medium by mixtures of bis(2,4,4-trimethylpentyl)phosphinic acid and 8hydroxyquinoline, Sep. Purif. Technol., 2012, 93, 48-51.

11 K. Larsson and K. Binnemans, Separation of Rare Earths by Solvent Extraction with an Undiluted Nitrate Ionic Liquid, Journal of Sustainable Metallurgy, 2017, 3, 73-78.

12 S. Satpathy and S. Mishra, Extractive separation studies of $\mathrm{La}(\mathrm{III})$ and $\mathrm{Ni}(\mathrm{II})$ in the presence of lactic acid using DEHPA in petrofin, Sep. Purif. Technol., 2017, 179, 513-522.

13 S. Yin, W. Wu, X. Bian and F. Zhang, Effect of complexing agent lactic acid on the extraction and separation of $\operatorname{Pr}(\mathrm{III}) / \mathrm{Ce}(\mathrm{III})$ with di-(2-ethylhexyl)phosphoric acid, Hydrometallurgy, 2013, 131, 133-137.

14 Y. Wang, Y. Xiong, S. Meng and D. Li, Separation of yttrium from heavy lanthanide by CA-100 using the complexing agent, Talanta, 2004, 63, 239-243.

15 J. Wang, G. Chen, S. Xu, Z. Yin and Q. Zhang, Solvent extraction of rare earth ions from nitrate media with new extractant di-(2,3-dimethylbutyl)-phosphinic acid, J. Rare Earths, 2016, 34, 724-730.

16 H. Naganawa, K. Shimojo, H. Mitamura, Y. Sugo, J. Noro and M. Goto, A new "green" extractant of the diglycol amic acid type for lanthanides, Solvent Extr. Res. Dev., Jpn., 2007, 14, 151-159.

17 A. M. Safiulina, A. G. Matveeva, A. V. Evtushenko, A. V. Lizunov, E. I. Goryunov, I. B. Goryunova, G. V. Bodrin, A. A. Semenov and V. K. Brel, Recovery of lanthanides from digested phosphogypsum solutions using a new organophosphorus extractant, 5(diphenylphosphoryl)hexan-3-one, Russ. J. Gen. Chem., 2015, 85, 2128-2134.
18 K. Larsson and K. Binnemans, Separation of rare earths by split-anion extraction, Hydrometallurgy, 2015, 156, 206-214.

19 T. Vander Hoogerstraete, S. Wellens, K. Verachtert and K. Binnemans, Removal of transition metals from rare earths by solvent extraction with an undiluted phosphonium ionic liquid: separations relevant to rareearth magnet recycling, Green Chem., 2013, 15, 919-927.

20 S. Riano and K. Binnemans, Extraction and separation of neodymium and dysprosium from used NdFeB magnets: an application of ionic liquids in solvent extraction towards the recycling of magnets, Green Chem., 2015, 17, 2931-2942.

21 R. Zarrougui, R. Mdimagh and N. Raouafi, Highly efficient and eco-friendly extraction of neodymium using, undiluted and non-fluorinated ionic liquids. Direct electrochemical metal separation, Sep. Purif. Technol., 2017, 175, 87-98.

22 Y. Xiong, W. Kuang, J. Zhao and H. Liu, Ionic liquid-based synergistic extraction of rare earths nitrates without diluent: Typical ion-association mechanism, Sep. Purif. Technol., 2017, 179, 349-356.

23 A. Rout and K. Binnemans, Efficient separation of transition metals from rare earths by an undiluted phosphonium thiocyanate ionic liquid, Phys. Chem. Chem. Phys., 2016, 18, 16039-16045.

24 N. K. Batchu, T. Vander Hoogerstraete, D. Banerjee and K. Binnemans, Non-aqueous solvent extraction of rareearth nitrates from ethylene glycol to n-dodecane by Cyanex 923, Sep. Purif. Technol., 2017, 174, 544-553.

25 E. Dziwinski and J. Szymanowski, Composition of CYANEX 923, CYANEX 925, CYANEX 921 and TOPO, Solvent Extr. Ion Exch., 1998, 16, 1515-1525.

26 M. Reddy, R. Varma, T. Ramamohan, S. Sahu and V. Chakravortty, Cyanex 923 as an extractant for trivalent lanthanides and yttrium, Solvent Extr. Ion Exch., 1998, 16, 795-812.

27 C. Tunsu, C. Ekberg, M. Foreman and T. Retegan, Studies on the Solvent Extraction of Rare Earth Metals from Fluorescent Lamp Waste Using Cyanex 923, Solvent Extr. Ion Exch., 2014, 32, 650-668.

28 C. Tunsu, M. Petranikova, C. Ekberg and T. Retegan, A hydrometallurgical process for the recovery of rare earth elements from fluorescent lamp waste fractions, Sep. Purif. Technol., 2016, 161, 172-186.

29 Y. A. El-Nadi, Effect of diluents on the extraction of praseodymium and samarium by Cyanex 923 from acidic nitrate medium, J. Rare Earths, 2010, 28, 215-220.

30 K. Binnemans and P. T. Jones, Solvometallurgy: An Emerging Branch of Extractive Metallurgy, Journal of Sustainable Metallurgy, 2017, 3, 570-600.

31 B. Onghena and K. Binnemans, Recovery of Scandium(III) from Aqueous Solutions by Solvent Extraction with the Functionalized Ionic Liquid Betainium Bis(trifluoromethylsulfonyl)imide, Ind. Eng. Chem. Res., 2015, 54, 1887-1898.

32 K. Klementev, Package "VIPER (visual processing in EXAFS researches) for windows", Nucl. Instrum. Methods Phys. Res., Sect. A, 2000, 448, 299-301. 
33 M. Newville, EXAFS analysis using FEFF and FEFFIT, $J$. Synchrotron Radiat., 2001, 8, 96-100.

34 S. Riano, M. Regadio, K. Binnemans and T. Vander Hoogerstraete, Practical guidelines for best practice on Total Reflection X-ray Fluorescence spectroscopy: Analysis of aqueous solutions, Spectrochim. Acta, Part B, 2016, 124, 109-115.

35 N. Akkus, J. Campbell, J. Davidson, D. Henderson, H. Miller, A. Parkin, S. Parsons, P. Plieger, R. Swart, P. Tasker and L. West, Exploiting supramolecular chemistry in metal recovery: novel zwitterionic extractants for nickel(II) salts, Dalton Trans., 2003, 1932-1940.

36 A. M. Wilson, P. J. Bailey, P. A. Tasker, J. R. Turkington, R. A. Grant and J. B. Love, Solvent extraction: the coordination chemistry behind extractive metallurgy, Chem. Soc. Rev., 2014, 43, 123-134.

37 J. R. Turkington, P. J. Bailey, J. B. Love, A. M. Wilson and P. A. Tasker, Exploiting outer-sphere interactions to enhance metal recovery by solvent extraction, Chem. Commun., 2013, 49, 1891-1899.

38 T. Yaita, H. Narita, S. Suzuki, S. Tachimori, H. Motohashi and H. Shiwaku, Structural study of lanthanides(III) in aqueous nitrate and chloride solutions by EXAFS, $J$. Radioanal. Nucl. Chem., 1999, 239, 371-375.

39 E. D. Doidge, I. Carson, J. B. Love, C. A. Morrison and P. A. Tasker, The Influence of the Hofmeister Bias and the Stability and Speciation of Chloridolanthanates on Their Extraction from Chloride Media, Solvent Extr. Ion Exch., 2016, 34, 579-593.

$40 \mathrm{Y}$. Marcus, Ions in solution and their solvation, Wiley, Hoboken, New Jersey, 2015.

41 S.-H. Yin, S.-W. Li, F. Xie, L.-B. Zhang and J.-H. Peng, Study on the aqueous solution behavior and extraction mechanism of $\mathrm{Nd}(\mathrm{III})$ in the presence of the complexing agent lactic acid with di-(2-ethylhexyl)phosphoric acid, $R S C$ Adv., 2015, 5, 64550-64556.

42 S. Yin, W. Wu, X. Bian, Y. Luo and F. Zhang, Solvent Extraction of $\mathrm{La}(\mathrm{III})$ from Chloride Medium in the Presence of Two Water Soluble Complexing Agents with di(2-ethylhexyl)Phosphoric Acid, Ind. Eng. Chem. Res., 2013, 52, 8558-8564.

43 M. Gernon, M. Wu, T. Buszta and P. Janney, Environmental benefits of methanesulfonic acid: Comparative properties and advantages, Green Chem., 1999, 1, 127-140.

44 I. Persson, P. D'Angelo, S. De Panfilis, M. Sandstrom and L. Eriksson, Hydration of lanthanoid(III) ions in aqueous solution and crystalline hydrates studied by EXAFS spectroscopy and crystallography: The myth of the "gadolinium break", Chem.-Eur. J., 2008, 14, 3056-3066.

45 Y.-S. Liu, M.-F. Tang and K.-H. Lii, Rare earth metal squarates incorporating ethylene glycol ligand with a three-dimensional framework structure: $\mathrm{RE}\left(\mathrm{C}_{4} \mathrm{O}_{4}\right)(1.5)\left(\mathrm{C}_{2} \mathrm{H}_{6} \mathrm{O}_{2}\right) \quad(\mathrm{RE}=\mathrm{Y}$, La-Nd, Sm-Lu), Dalton Trans., 2009, 9781-9786.

46 Z. Spichal, B. Hegrova, Z. Moravec, J. Pinkas and M. Necas, Synthesis and structure of lanthanide complexes with large-bite diphosphine dioxide ligands, Polyhedron, 2011, 30, 1620-1627.

47 A. Bowden, P. N. Horton and A. W. G. Platt, Lanthanide Nitrate Complexes of Tri-Isobutylphosphine Oxide: Solid State and $\mathrm{CD}_{2} \mathrm{Cl}_{2}$ Solution Structures, Inorg. Chem., 2011, 50, 2553-2561.

48 M. Glazier, W. Levason, M. Matthews, P. Thornton and M. Webster, Synthesis, properties and solution speciation of lanthanide chloride complexes of triphenylphosphine oxide, Inorg. Chim. Acta, 2004, 357, 1083-1091. 